\title{
High School Graduates' Perceptions of Factors that Will Impact Academic Success in College
}

\author{
Annie M. Cole, University of Portland
}

The present study used mixed-methods, retrospective causal-comparison research design to analyze the perceptions of 1,400 high school graduates who had been admitted to college, exploring the factors that students believed would impact their academic success in college. A qualitative analysis of narrative survey responses revealed six themes of perceived factors: academic interests, access to resources, learner identity, non-academic activities, personal factors, and social transition. Student perceptions differed significantly by demographic variables: firstgeneration status, gender, and second-year college retention. Suggestions for implementation of results into high school and first-year college programming are offered.

Keywords: High-School Graduates, First-Year College Students, Student Perceptions, College Success

High school counselors, teachers, and administrators are well aware of factors that are linked to students' future academic success in college, including high school GPA and ACT scores (Noble \& Sawyer, 2002), age (Ross, 2003), first-generation (FGEN) status (Fry \& Lopez, 2012; Kim et al., 2010; Roderick et al., 2009), social support (Dennis et al., 2005), sense of belonging and self-efficacy (Han et al., 2017), and experiences of mental health, especially anxiety and depression (Eisenberg et al., 2009). Knowledge of these factors is used to inform supportive programming for high schoolers as they prepare for their transition to college.

Although the body of literature offers great insight into factors that are linked to college student success, the majority of studies have focused on the relationship between student factors (age, ACT score) and academic outcomes in college (college GPA, retention) without reference to student perceptions about these factors and outcomes. There is a gap in the literature related to the perceptions that high school graduates hold about factors that will impact their academic performance in college, and it's unclear whether students perceive these same factors as impactful to their future college success. Since student perceptions can impact successful college performance and persistence (Bandura, 1986) and predict academic outcomes, such as first-semester GPA (Boulter, 2002), it's essential to explore the perceptions that high schoolers hold about their upcoming transition to college.

The purpose of this study was to explore the perceptions of recent high school graduates who had been admitted to college, determining which factors students believed would impact their academic success in college, and determining if these perceived factors differed according to demographic variables: students' FGEN status, self-identified gender, and second-year retention status. This study provides educators with a deeper understanding of student perceptions and explores whether student perceptions are aligned with the factors identified in the literature. The results of this study can be used to inform and improve programming for high school seniors as they transition to college, resulting in more effective supports for students. 


\section{Literature Review:}

\section{Understanding Factors that Impact Academic Success in College}

Factors linked to academic success in college have been widely studied in the literature, with associations found to exist between college academic success and demographic, social, psychosocial, and university factors. The range of factors identified in the literature are outlined below, providing a framework through which the results of this study can be interpreted. For the purpose of this paper, the term "academic success" refers to college retention, college adjustment, and academic GPA in college. First-year retention is defined as continuous enrollment in the university through the first year of college until the census date of the second year. College adjustment is defined as "the opposite of transition trauma" (Bennett \& Okinaka, 1990, p. 39), when students begin to feel a lack of alienation and become familiar with university norms and expectations. Academic GPA in college is defined as the calculated grade point average.

\section{Demographic Factors}

Demographic factors, including FGEN college student status and ethnicity, can impact academic success in college (Kim et al., 2010). Income and FGEN status, especially for African American and Latino students, impacts retention (Fry \& Lopez, 2012; Roderick et al., 2009). Additional retention variables include race, residency, high school GPA (Murtaugh et al., 1999), and sex (Voorhees, 1987).

Age can also influence retention and academic outcomes. For example, nontraditional students identified as older, part-time, or commuter students are more likely to be retained if they are satisfied with environmental factors; social integration is less important to retention for nontraditional students (Bean \& Metzner, 1985). A weak correlational relationship also exists between age and academic success; as age goes up, GPA goes up for college students (Ross, 2003).

\section{Social Adjustment and Belonging}

Students who feel they belong on campus, meaning they report feelings of academic and social support, are more likely to continue in their education (Gerdes \& Mallinckrodt, 1994; Han et al., 2017). College freshmen's sense of belonging significantly predicts academic and psychological adjustment to college, and certain populations (minoritized ethnicities, low-income, and FGEN students) tend to experience less sense of belonging than their white classmates (Pittman \& Richmond, 2007).

Tinto's (1987) study of student retention revealed that student integration into the university, socially and academically, influences drop-out decisions. Social adjustment as early as the third week of college significantly predicts five-year degree completion rate (Woosley, 2003), and adjustment to college, measured by student academic progress and intention to remain enrolled, predicts academic performance (Chemers et al., 2001). Lack of social supports (family and peers) correlates with college outcomes, including college adjustment, college commitment, and GPA (Dennis et al., 2005).

\section{Psychosocial Skills, Mindset, and Self-Efficacy}

Psychosocial skills are more predictive of college outcomes (cumulative GPA and retention) over time than socioeconomic status or high school GPA (Robbins et al., 2004). Academic mindsets, which include academic motivation and self-efficacy levels, have been found to predict academic performance (Chemers et al., 2001) and first-year student retention (Farruggia et al., 2018). Students who report high scores along scales of perceived 
academic self-efficacy, sense of belonging, and academic motivation are most likely to be academically successful and stay in college. Successful academic performance in college is also related to non-cognitive factors including academic behaviors, academic perseverance, academic mindsets, learning strategies, social skills (Farrington et al., 2012), and self-control (Cantwell \& Moore, 1996).

Student beliefs, perceptions, and goals similarly impact college outcomes. Dweck (1986) finds that students' beliefs regarding intelligence impact academic success, with students generally holding either a fixed mindset, believing that intelligence is not changeable, or a growth mindset, believing that intelligence can be developed over time. Student mindset, along with sense of belonging, impacts educational outcomes for students (Rattan et al., 2015). Students who have high internal levels of Locus of Control (LOC), the level of control an individual believes they have over life events (Rotter, 1966), perform better academically (Gifford et al., 2006; Landine \& Stewart, 1998), while students who have unclear goals, including indecision about major or career plans, are more likely to drop out of college (Anderson, 1985; Noel, 1985). Student goals related to purpose for enrollment and intent to return are significantly associated with retention (Voorhees, 1987).

\section{University Fit and Satisfaction}

The way students perceive themselves and their fit with the environment around them greatly impacts the way they experience college. Li et al. (2012) studied student perceived institutional fit as a potential predictor of well-being and academic outcomes. Results showed that students who perceived themselves as high in Student Interests-Major fit (congruence between students' interests and characteristics of a major) were least likely to change their major, while students perceiving themselves as high in Academic Capabilities-Academic Demands fit (congruence between students' capabilities and the demands of schoolwork) had the highest academic performance scores (final semester GPA).

Satisfaction is related to retention, with students who showed higher satisfaction with university processes (access to information, interactions with staff and faculty) remaining enrolled for a second semester of college (Heverly, 1999). Schertzer and Schertzers' (2004) consumer-oriented model of student retention emphasizes the need to satisfy students with the college experience, acknowledging the importance of academic fit, studentinstitution value congruence, student-faculty value congruence, and institutional commitment to increase the chance of retention.

\section{Social-Emotional Factors}

Emotional, social, and academic adjustment can significantly impact retention. Students who successfully adjusted to college emotionally and socially are more likely to stay in school than those who made a successful transition academically into college. In fact, academic factors explain less than $50 \%$ of student dropout decisions. Academic and emotional adjustment play slightly different roles in students' lives depending on their academic performance, which makes the study of adjustment and development complex. Students who are successful academically tend to stay in school if they enjoy their classes and have access to their professors, whereas students with lower grades are more likely to stay in school if they have built connections with campus staff and are satisfied with activities outside of the classroom (Gerdes \& Mallinckrodt, 1994).

\section{Mental Health Issues}

Ranging from stress to suicidal thoughts, mental health experiences can directly impact student attrition 
and success. A two-year study between 2005 and 2007 found that co-occurring depression and anxiety, as well as stand-alone depression, predicted lower GPA and increased student drop-out rates (Eisenberg et al., 2009). Another study found that students who experienced suicidal ideation within the past 12 months obtained a lower cumulative GPA on average when compared to students who had not experienced suicidal ideation (De Luca et al., 2016).

Experiences of mental health issues can range from social anxiety and hopelessness to depression and suicidal thoughts. One survey at a large public university found that $16 \%$ of undergraduates had experienced anxiety or depression, and $2 \%$ of all students (undergraduate and graduate) had thoughts of suicide within the past 4 weeks (Eisenberg et al., 2007). A 2017 survey administered by the American College Health Association collected data about mental health experiences of 31,463 college students at 52 colleges. Sixty-one percent of students reported feeling overwhelming anxiety at some point within the past year, and $52 \%$ reported feelings of hopelessness (American College Health Association, 2017).

\section{Students with Disabilities}

Students with disabilities are less likely to reach degree completion (deFur et al., 1996). Students with ADHD experience moderate to large differences in academic performance in comparison to students without ADHD (Frazier et al., 2007), and students with ADHD are at greater risk of low grades and school attrition (Fergusson \& Horwood, 1995).

Understanding Student Perceptions of These Factors

The literature provides a breadth of studies on the factors that predict, or correlate with, student academic success in college. Many studies have explored specific relationships between one or two factors and a college outcome. The present study seeks to build upon the previous literature by exploring the entire range of factors that students perceive as impactful to their college success.

Additionally, previous studies have not considered the perception of students in relation to these college success factors. This study offers educators insight into the perceptions of students to see if student thinking is similar to findings in college success literature. The qualitative approach of this study also offers unique insight into student perceptions, which is missing from the mostly quantitative studies of the past.

\section{Methods}

The purpose of this mixed-methods, retrospective causal-comparison study was twofold: 1) to explore the factors that high school graduates perceive will impact their academic success in college, and 2) to determine if these perceived factors differ by students' FGEN status, self-identified gender, and second-year retention status. The data sources for this study included open-ended narrative answers from an electronic survey and demographic information (FGEN status, self-identified gender, and second-year retention status) pulled from the university central data system (Banner).

The researcher used narrative inquiry methodology to explore 1,400 participant narrative survey responses, revealing five themes in the data. Following the narrative inquiry process, participant narrative responses were sorted by the five themes. These five themes were then compared to the three demographic variables (FGEN status, gender, and second-year retention status) through statistical analysis to determine differences in responses by groups. 


\section{Sample}

The study sample included 2,883 high school graduates who had been admitted to a small, private university on the west coast of the United States across three years. The sample included all first-year students admitted in fall 2015 ( $\mathrm{n}=933$ ), fall 2016 ( $\mathrm{n}=952$ ), and fall 2017 ( $\mathrm{n}=998$ ) to the university. Participants identified their gender as one of two options on the survey: $61 \%$ identified as female $(n=1745)$ and $39 \%$ identified as male $(\mathrm{n}=1138)$. Of the 2,883 total students, $7 \%(\mathrm{n}=202)$ identified as FGEN status. Of the 2,883 total students, 1112 (39\%) did not answer the open-ended survey question, and 371 (13\%) responded "N/A" or responded that they had nothing to share in response to this question. This left 1,400 narrative student responses for analysis.

\section{Instrument}

This study used two instruments for data collection: an electronic survey dispersed via email, and the university central data system. The survey was created in collaboration by the academic resource center and institutional research office at the university, based on factors that had been previously identified as predictive of academic performance and college retention. Each summer prior to the first semester of enrollment, all admitted, incoming first-year students were asked to complete the survey to inform college staff about past academic experiences and current college interests. The survey was sent to students' university email accounts from the academic resource center. The survey included 275 questions in total.

The present study extracted data collected by three of the questions on the survey. Two survey questions determined FGEN status: "What is the highest level of education your mother/guardian 1 completed?" and "What is the highest level of education your father/guardian 2 completed?" If highest level of education for both guardians was reported as high school or lower, the participant was coded as FGEN.

One open-ended survey question captured students' perceptions of factors that will impact academic success during college: "What other information do you feel your advisor should know about you that might affect your academic performance at [school name]?"

Two additional data points were extracted from the university central data system (Banner) to include in the study. Gender was collected through the admissions application and stored in Banner. Retention status was captured on the census date of the second year of enrollment by the academic resource center and stored in Banner. If a student was continuously enrolled at the university on the census data of their second year at the university, they were coded as retained. If not, the student was coded as not retained. These data points were extracted by academic resource center staff from Banner, merged with the narrative data from the openended survey question, and released by email in Excel format to the researcher. All identifying information was removed, including student names and IDs, prior to being released to the researcher.

\section{Data Analysis}

Data analysis was performed to answer four research questions:

1. What factors do high school graduates perceive will impact their academic success in college?

2. Do factors that high school graduates perceive will impact their academic success in college differ by FGEN status?

3. Do factors that high school graduates perceive will impact their academic success in college differ by gender? 
4. Do factors that high school graduates perceive will impact their academic success in college differ by second-year retention status?

Narrative analysis was used to answer the first research question, guided by Saldana's (2016) qualitative data analysis framework. Data coding took place in three phases. To ensure credibility and trustworthiness of the narrative inquiry process, the researcher elicited the support of a professor of qualitative research at the university after each of the three coding cycles. First, in vivo coding was used to explore the essence of student narrative responses, with the purpose of maintaining the original intent of the participant's response. Quotes and key words were pulled out of each narrative response, resulting in the first list of codes. Second, the researcher reviewed the in vivo codes over multiple days and reflected on descriptive codes that matched the in vivo codes. Descriptive codes were then assigned to each participant's response. Third, the researcher reviewed the descriptive codes, which informed the development of the six themes.

To answer research questions two through four, statistical analysis using chi-square was performed to analyze the relationship between the six narrative themes and the three quantitative variables.

\section{Results}

Narrative inquiry was used to answer the first research question: What factors do high school graduates perceive will impact their academic success in college? Six themes emerged from the data analysis: academic interests, access to resources, learner identity, non-academic activities, personal factors, and social transition. If more than one theme could be assigned to an individual student's response, that response was assigned to all applicable themes.

\section{Personal Factors}

High school graduates believed that personal factors would impact their future college academic success, with narratives assigned to this theme including descriptive codes such as medical, mental, home life, and personal attributes. Students shared perceptions about mental health issues impacting their success ("If my mental health decreases, so does my studies") and medical issues ("I have chronic migraines that sometimes make it difficult for me to focus"). For others, issues at home were perceived as most impactful. One student stated, "I have some family issues going on with my parents." Another shared, "my mom has cancer." Personal attributes, including personality traits, were mentioned: "Some say I'm an overthinker," "I'm typically very quiet," and "I struggle with making decisions." Students referred to positive attributes, such as being hardworking and passionate, as well as negative attributes, including lack of motivation and being easily distracted. This theme encompassed student perceptions related to home, health, and personal identity; in other words, who the student is and the experiences and issues they bring to college.

\section{Learner Identity}

Learner identity was the second theme to emerge from the data. This theme referred to student perceptions about how their abilities, prior academic experiences, and academic identity would impact academic success in college. Narratives under this theme were assigned descriptive codes such as academic abilities and disabilities, learning identity, high school experiences, and academic perceptions. Students shared specific learning disabilities that they had been diagnosed with, including dyslexia, ADD, and ADHD. Others talked about their ability to do academic work: "I have good study habits" and "I am better at the arts than the sciences." Students described how who they are as a learner impacts their success, with one student stating, "I have what it takes 
to acquire A's." Students shared both positive and negative factors, such as, "I am quite a passionate learner" and "I have been known to procrastinate." A few students referred to their high school experiences and how they prepared them for college: "I go to a college preparatory high school" and "I am very accustomed to a high standard of rigor."

\section{Academic Interests}

Academic interests were also perceived as impactful to high school graduates' future academic success. Descriptive codes under this theme included career interests, academic interests, and academic preferences. Academic interests referred to interests in majors, minors, and academic programs such as ROTC or study abroad. Within this theme, students made connections between their academic interests and preferences, and how these things would impact their workload or timeline to graduation. One student shared, "I have many interests such as sports, music, spiritual life, and clubs. I will need to make sure I can manage my time well." Another stated, "I worry most about balancing sports, sleep, social and schoolwork." Many students mentioned a desire to balance or manage multiple interests while also remaining successful academically. Career interests were similarly mentioned in relationship to the concept of time management; students wanted to choose a career path that was feasible within four years, or achievable in combination with other academic interests.

\section{Non-Academic Activities}

The theme of non-academic activities emerged next, including the descriptive codes extracurricular interests, social events, college athletics, work, and internships. Students perceived these events as impactful to their time and availability to get academic work done for their degree. For example, student athletes expressed concern about their sports schedule impacting their overall schedule: "I would like to know how being on a sport time changes my day to day schedule." Other students expected their extracurricular activities to impact their academics, with mentions of engaging in too many activities to the point of overwhelm: "I have a tendency to over commit myself because I want to be involved in so many different activities" and "I tend to take on to[o] many activities and occasionally it affects my studies." Other students prioritized social activities and expressed a desire to balance social and academic activities: "I want to be studious and learn, but at the same time I want to be social, and have time for fun activities."

\section{Access to Resources}

The fifth theme that emerged from the data was access to resources, which included academic, personal, and financial resources. Interestingly, students mentioned both an interest in accessing resources, as well as a fear about not taking initiative and accessing resources when needed. Students who expressed interests in utilizing resources to impact their academic success made statements such as, "I would like to get as much help as possible" and "I would love to be involved into a study group or class or club. I think this will help me during school." Students who believed they would avoid utilizing resources when needed shared, "I am not very good at asking questions because I'm afraid of looking stupid or embarrassing myself" and, "I sometimes have a hard time asking for help when I need it." One student mentioned both an interest and a hesitancy in using resources: "[I] could use some help with studying. Also, I am not good at asking questions when I need help." 


\section{Social Transition}

Lastly, the theme of social transition emerged from the data, with participants referring to descriptive codes such as homesickness, worry about making friends, and worry around successfully transitioning to college and feeling a sense of belonging. Some students were moving far away from home ("I am new to the area as well as the state") and worried about missing home ("being homesick is one of my main worries"). Others shared concern about adjusting to the college environment: "I am just a little worried about the drastic change," "I am not sure how I will handle the change to a collegiate setting with a completely new academic system," and "I am nervous because this will be my first time sharing a room with someone else." Social connection was mentioned in many narratives, with students expecting difficulty in making friends or fitting in: "I am nervous about making friends" and "I might feel a bit lonely because I won't know anyone there at the school."

\section{Do Factors Perceived as Impacting Academic Success Differ by Demographics?}

To answer research questions two through four, do factors perceived as impacting academic success differ by FGEN status, gender, or retention status, statistical analysis using chi-square was performed. A frequency count for each of the six themes was done in preparation for chi-square analysis. If an individual student's response could be assigned to more than one theme, it was assigned to all applicable themes. Table 1 displays the total number of individual student responses within the sample $(n=1400)$ that were assigned to each theme extracted during the theming phase of analysis.

\section{Table 1}

Count of Participants Assigned to Each Theme

\begin{tabular}{lll}
\hline Perceived theme & $\mathrm{n}$ & $\%$ \\
\hline Personal Factors & 510 & $36 \%$ \\
Learner Identity & 505 & $36 \%$ \\
Academic Interests & 289 & $21 \%$ \\
Non-Academic Activities & 237 & $17 \%$ \\
Access to Resources & 156 & $11 \%$ \\
Social Transition & 115 & $8 \%$ \\
\hline
\end{tabular}

\section{Factors Perceived as Impacting Academic Success by First-Generation Status}

Of the 2,883 participants in the sample, $7 \%(\mathrm{n}=202)$ were coded as FGEN status. A chi-square analysis revealed that student perceptions of one of the six themes differed by FGEN status: access to resources. FGEN students had a higher than expected count of this theme, while non-FGEN students had a lower than expected count, $\chi^{2}(1, \mathrm{~N}=2883)=3.83, \mathrm{p}=.05$. Table 2 displays the expected and actual counts of this theme by FGEN status. 
Table 2

Expected and Actual Count of Participants Assigned to Each Theme by FGEN Status

\begin{tabular}{lll}
\hline Perceived theme & FGEN & Non-FGEN \\
\hline Access to Resources: Expected & 10.9 & 145.1 \\
Access to Resources: Actual & 17 & 139 \\
\hline
\end{tabular}

\section{Factors Perceived as Impacting Academic Success by Gender}

Of the 2,883 participants in the sample, $61 \%$ identified as female $(n=1745)$ and $39 \%$ identified as male ( $\mathrm{n}=1138)$. A chi-square analysis revealed that student perceptions of one theme differed by retention status: personal factors. Female-identified students had a higher than expected count of personal factors, while maleidentified students had a lower than expected count, $\chi^{2}(1, N=2883)=18.70, p<.001$. Interestingly, a chi-square analysis also revealed that male-identified students had a higher than expected count of N/A responses, while female-identified students had a lower than expected count, $\chi^{2}(1, N=2883)=8.46, p=.004$. Table 3 displays the expected and actual counts of these themes by gender.

\section{Table 3}

Expected and Actual Count of Participants Assigned to Each Theme by Gender

\begin{tabular}{lll}
\hline Perceived Theme & Female & Male \\
\hline Personal Factors: Expected & 308.7 & 201.3 \\
Personal Factors: Actual & 352 & 158 \\
N/A: Expected & 224.6 & 146.4 \\
N/A: Actual & 199 & 172 \\
\hline
\end{tabular}

Factors Perceived as Impacting Academic Success by Retention Status

Of the 2,883 participants in the sample, 2,590 (90\%) were retained from first-year fall semester to secondyear fall semester, while 293 (10\%) were not retained. A chi-square analysis revealed that student perceptions of one theme differed by retention status: personal factors. Students who were not retained had a higher than expected count of this theme, while retained students had a lower than expected count, $\chi^{2}(1, N=2883)=3.86, p$ $=.049$. Table 4 displays the expected and actual counts of this theme by retention status.

\section{Table 4}

Expected and Actual Count of Participants Assigned to Each Theme by Retention Status

\begin{tabular}{lll}
\hline Perceived theme & Retained & Not Retained \\
\hline Personal Factors: Expected & 458.2 & 51.8 \\
Personal Factors: Actual & 446 & 64 \\
\hline
\end{tabular}




\section{Discussion}

The present study explored factors that high school graduates perceive will impact their academic success in college and determined if these perceived factors differed by students' FGEN status, self-identified gender, and second-year retention status. Narrative analysis of participant responses revealed six themes of perceived factors that will impact college academic success: academic interests, access to resources, learner identity, nonacademic activities, personal factors, and social transition.

Statistical analyses revealed that student perceptions of factors impacting college academic success differed significantly by the three demographic groups. FGEN students had significantly higher than expected perceptions of the theme access to resources as impactful to success. Female-identified students had significantly higher than expected perceptions of personal factors as impactful to college academic success, while male-identified students had significantly higher N/A responses than expected (stating that they had nothing to share in response to the survey question). Students who were not retained for the second year of college had significantly higher than expected perceptions of personal factors as impactful to college academic success.

The six themes that emerged from the data were consistent with previous findings in the college academic success literature, suggesting that student perceptions about academic success in college are consistent with factors that are top of mind for high school and college educators. For example, within the theme of personal factors, participants perceived mental health as a factor that would impact their academic success in college, supported by Eisenberg et al.'s study (2009). Participants also expect high school academic experience, social adjustment, and self-efficacy to impact their academic success in college, three topics that are reflected in other scholars' findings (Chemers et al., 2001; Farruggia et al., 2018; Gerdes \& Mallinckrodt, 1994; Han et al., 2017; Murtaugh et al., 1999).

Although student perceptions were found to correspond with previous literature, the present study offers unique insight into the frequency at which students perceive these factors as impactful. For example, the results suggest that more students are expecting personal factors and learner identity to impact their success in college. If this is a common perception for most students, then high school educators should be mindful about discussing these perceptions with students and providing accurate supports before and during the transition to college.

The results also offer insight into the perceptions of specific student populations. Students who are not retained for a second year had higher than expected perceptions of personal factors being impactful to academic success. This may suggest that students who perceive personal factors as impactful are more at risk for attrition after the first-year of college. Higher educators can use this information to identify students at risk of attrition and provide proactive supports and resources.

\section{Practical Implications}

The present study offers high school and first-year college staff, administrators, and teachers a glimpse into the perceptions of high school graduates preparing for the transition to college. By understanding the perceptions of students, educators can respond proactively and create programs and practices that respond to these perceptions, leading to increased student success, satisfaction, and retention. Education professionals are often knowledgeable of factors that researchers have identified as impactful to academic success while neglecting to understand student perceptions of these factors. The researcher encourages educators to consider academic success factors through the eyes of students, and to approach programming, teaching, and advising with the understanding that students have different factors at the forefront of their minds than staff and faculty do. 
Providing students with supports and resources related to their most common perceived barriers (personal factors and learner identity) is essential. Universities can support students by having conversations about students' perceptions, especially factors that aren't usually mentioned in conversation: mental health issues, academic preferences, and learning identity. Educators must realize that student perceptions of themselves as learners refers more to who students are ("I will try hard, and that's what makes me successful," "I'm not the best student, but I'm motivated to change") than their academic record (GPA and test scores). Recognizing these perceptions and discussing them with students can be a powerful way to acknowledge student voices and support their academic success, especially if the perceptions are negative.

\section{Limitations and Future Direction}

The present study is limited by its data collection methodology. The researcher utilized a survey that was sent to admitted, incoming first-year college students from an academic resource center on campus. Students may not have responded honestly to the survey if they desired to present themselves in a specific way to campus staff. However, the narrative responses received through the survey included intimate details of student perceptions and were more thorough than the researcher expected.

Future research is needed to further explore the narratives within each of the six identified themes. Within the FGEN student narratives, further study should examine the breakdown of descriptive codes; are FGEN students perceiving the access to resources as most impactful, or the avoidance of resources as most impactful, to academic success? Further exploration within the theme of personal factors is also needed, detailing the breakdown of personality traits perceived by students as impactful to academic success.

Lastly, future research is needed to explore student perceptions of mental health as a factor impacting academic success. Mental health was a descriptive code under the theme of personal factors. This descriptive code was assigned to $16 \%$ of the 1,400 participants $(n=223)$, making it the most frequent descriptive code in the study. Interestingly, a 2007 study also found that $16 \%$ of undergraduates had experienced anxiety or depression within the past 4 weeks (Eisenberg et al.). This may suggest that this frequency of mental health experiences in the undergraduate college population is similar across universities.

\section{Conclusion}

The present study offers important insight into the perceptions of high school graduates preparing for their first year of college. The results suggest that students expect six themes of factors to impact their future college success: academic interests, access to resources, learner identity, non-academic activities, personal factors, and social transition. In particular, a large portion of the sample perceived personal factors and learner identity as impactful to academic success in college. These perceptions can inform high school and first-year college student programming and offer wisdom to educators who will interact with students throughout the summer and fall of the first college year. Educators are encouraged to consider academic success factors through the eyes of students, and to approach programming, teaching, and advising with the understanding that students have different factors at the forefront of their minds than staff and faculty do. 


\section{References}

American College Health Association. (2017). American College Health Association-National College Health Assessment II: Fall 2017 Reference Group Executive Summary.

Anderson, E. (1985). Forces influencing student persistence and achievement. In L. Noel, R. Levitz, D. Saluri, \& Associates (Eds.), Increasing student retention: Effective programs and practices for reducing the dropout rate. San Francisco, CA: Jossey-Bass.

Bandura, A. (1986). The explanatory and predictive scope of self-efficacy theory. Journal of Social and Clinical Psychology, 4, 359-373.

Bean, J. P., \& Metzner, B. S. (1985). A conceptual model of nontraditional undergraduate student attrition. American Educational Research Association, 55(4), 485-540.

Bennett, C., \& Okinaka, A. M. (1990). Factors related to persistence among Asian, black, Hispanic, and white undergraduates at a predominantly white university: Comparison between first and fourth year cohorts. The Urban Review, 22(1), 33-60.

Boulter, L. T. (2002). Self-concept as a predictor of college freshman academic adjustment. College Student Journal, 36(2), 234-246.

Cantwell, R. H., \& Moore, P. J. (1996). The development of measures of individual differences in self-regulatory control and their relationship to academic performance. Contemporary Educational Psychology, 21(4), 500-517.

Chemers, M. M., Hu, L., \& Garcia, B. F. (2001). Academic self- efficacy and first-year college student performance and adjustment. Journal of Educational Psychology, 93(1), 55-64.

deFur, S. H., Getzel, E. E., \& Trossi, K. (1996). Making the postsecondary education match: A role for transition planning. Journal of Vocational Rehabilitation, 6(1), 231-241.

De Luca, S. M., Franklin, C., Yueqi, Y., Johnson, S., \& Brownson, C. (2016). The relationship between suicide ideation, behavioral health, and college academic performance. Community Mental Health Journal, 52(5), 534-540.

Dennis, J. M., Phinney, J. S., \& Chuateco, L. I. (2005). The role of motivation, parental support, and peer support in the academic success of ethnic minority FGEN college students. Journal of College Student Development, 46(3), 223-36

Drago, A., Rheinheimer, D. C., \& Detweiler, T. N. (2018). Effects of locus of control, academic self-efficacy, and tutoring on academic performance. Journal of College Student Retention: Research, Theory, \& Practice, 19(4), 433-451.

Dweck, C. S. (1986). Motivational processes affecting learning. American Psychologist, 41, 1040-1048.

Eisenberg, D., Golberstein, E., \& Hunt, J. B. (2009). Mental health and academic success in college. The B.E. Journal of Economic Analysis and Policy, 9(1), 1-35

Eisenberg, D., Gollust, S. E., Golberstein, E., \& Hefner, J. L. (2007). Prevalence and correlates of depression, anxiety, and suicidality among university students. American Journal of Orthopsychiatry, 77(4), 534-542

Farrington, C. A., Roderick, M., Allensworth, E., Nagaoka, J., Johnson, D. W., \& Beechum, N. O. (2012). Teaching adolescents to become learners: The role of non-cognitive factors in shaping school performance: A critical literature review. University of Chicago Consortium on School Research. 
Farruggia, S. P., Han, C., Watson, L., Moss, T. P., \& Bottoms, B. L. (2018). Noncognitive factors and college student success. Journal of College Student Retention, 20(3), 308-327.

Fergusson, D. M., \& Horwood, L. J. (1995). Early disruptive behavior, IQ and later school achievement and delinquent behavior. Journal of Abnormal Child Psychology, 23(2), 183-199.

Frazier, T. W., Youngstrom, E. A., Glutting, J. J., \& Watkins, M. W. (2007). ADHD and achievement: Meta-analysis of the child, adolescent, and adult literatures and a concomitant study with college students. Journal of Learning Disabilities, 40(1), 49-65.

Fry, R., \& Lopez, M. (2012). Hispanic enrollment reaches new highs in 2011. Washington, DC: Pew Hispanic Center.

Gerdes, H., \& Mallinckrodt, B. (1994). Emotional, social, and academic adjustment of college students: A longitudinal study of retention. Journal of Counseling and Development, 72(3), 281-288.

Gifford, D. D., Briceno-Perriott, J., \& Mianzo, F. (2006). Locus of control: Academic achievement and retention in a sample of university first-year students. Journal of College Admission, 191(1), 18-25.

Han, C., Farruggia, S. P., \& Moss, T. P. (2017). Effects of academic mindsets on college students' achievement and retention. Journal of College Student Development, 58(8), 1119-1134.

Heverly, M. A. (1999). Predicting retention from students' experiences with college processes. Journal of College Student Retention, 1(1), 3-11.

Kim, E., Newton, F., Downey, R., \& Benton, S. (2010). Personal factors impacting college student success: Constructing college learning effectiveness inventory (CLEI). College Student Journal, 44(1), 112-125.

Landine, J., \& Stewart, J. (1998). Relationship between metacognition, motivation, locus of control, self-efficacy, and academic achievement. Canadian Journal of Counseling, 32(3), 200-212.

Li, Y., Yao, X., Chen, K., \& Wang, Y. (2012). Different fit perceptions in an academic environment: Attitudinal and behavioral outcomes. Journal of Career Assessment, 21(2), 163-174.

Murtaugh, P. A., Burns, L. D., \& Schuster, J. (1999). Predicting the retention of university students. Research in Higher Education, 40(3), 355-371.

National Alliance on Mental Illness (2012). College students speak: Survey report on mental health. Retrieved from https://www.nami.org/getattachment/About-NAMI/Publications-Reports/Survey-Reports/CollegeStudents-Speak_A-Survey-Report-on-Mental-Health-NAMI-2012.pdf

Noble, J., \& Sawyer, R. (2002). Predicting different levels of academic success in college using high school GPA and ACT composite score. Iowa City, IA: ACT.

Noel, L. (1985). Increasing student retention: New challenges and potential. In L. Noel, R. Levitz, D. Saluri \& Associates (Eds.), Increasing student retention: Effective programs and practices for reducing the dropout rate. San Francisco, CA: Jossey-Bass.

Rattan, A., Savani, K., Chugh, D., \& Dweck, C. (2015). Leveraging mindsets to promote academic achievement: Policy recommendations. Perspectives on Psychological Sciences, 10(6), 721-726.

Pittman, L. D., \& Richmond, A. (2007). Academic and psychological functioning in late adolescence: The importance of school belonging. The Journal of Experimental Education, 75(4), 270-290

Robbins, S. B., Lauver, K., Le, H., Davis, D., Langley, R., \& Carlstrom, A. (2004). Do psychosocial and study skill factors predict college outcomes? A meta-analysis. Psychology Bulletin, 130(2), 261-288.

Roderick, M., Nagaoka, J., \& Coca, V. (2009). College readiness for all: The challenge for urban high schools. The Future of Children, 19(1), 185-210. 
Ross, T. R. (2003). Retention implications of a relationship between age and GPA. College Student Journal, 37(2), 181-189.

Rotter, J. B. (1966). Generalized expectancies for internal versus external control of reinforcement. Psychological Monographs: General and Applied, 80(1), 1-27.

Saldana, J. (2016). The coding manual for qualitative researchers (2nd ed.). Los Angeles, CA: Sage Publications.

Schertzer, C. B., \& Schertzer, S. M. B. (2004). Student satisfaction and retention: A conceptual model. Journal of Marketing for Higher Education, 14(1), 79-91.

Tinto, V. (1987). Leaving college: Rethinking the causes and cures of student attrition. Chicago, IL: University of Chicago Press.

Voorhees, R. A. (1987). Toward building models of community college persistence. Research in Higher Education, 26(2), 115-129.

Woosley, S. A. (2003). How important are the first few weeks of college? The long term effects of initial college experiences. College Student Journal, 37(2), 201-207. 